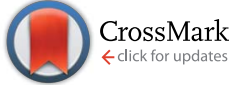

Cite this: RSC Adv., 2015, 5, 45767
Received 7th April 2015

Accepted 14th May 2015

DOI: $10.1039 / \mathrm{c} 5 \mathrm{ra06146f}$

www.rsc.org/advances

\section{One-pot synthesis of a polyaniline-gold nanocomposite and its enhanced electrochemical properties for biosensing applications $\uparrow$}

\begin{abstract}
Amrita Soni, Chandra Mouli Pandey, Shipra Solanki and Gajjala Sumana*
One pot synthesis of a polyaniline-gold (PANI-Au) nanocomposite has been conducted using a chemical route in the presence of dodecyl benzene sulfonic acid. This PANI-Au nanocomposite was electrophoretically deposited onto indium tin oxide (ITO) coated glass substrates and the electrochemical kinetics were compared with chronopotentiometrically deposited PANI-Au (in the presence of $\mathrm{HCl}$ ) composite. The electrochemical results indicate that the composite prepared by the chemical route exhibits an enhanced electron transfer coefficient $(\alpha)$ of 0.92 and charge transfer rate constant $\left(k_{\mathrm{s}}\right)$ of $0.0848 \mathrm{~s}^{-1}$ as compared to the film deposited using the chronopotentiometric technique $\left(\alpha=0.85\right.$ and $\left.k_{\mathrm{s}}=0.0368 \mathrm{~s}^{-1}\right)$. These fabricated matrices have been further utilized as biosensing platforms for the detection of sexually transmitted disease. The PANI-Au based genosensor has demonstrated enhanced sensitivity $\left(10^{-16} \mathrm{M}\right.$; linear range from $10^{-6}$ to $\left.10^{-16} \mathrm{M}\right)$ with a response time of $60 \mathrm{~s}$ and shows excellent specificity over other bacterial pathogens. The results of these studies help in understanding the method of synthesis on the electrochemical as well as catalytic properties of the composite and its potential for a wide range of biomedical applications.
\end{abstract}

\section{Introduction}

Conducting polymers and their nanocomposites have aroused much interest in recent years due to their good electrical conductivity, redox properties, ease of synthesis, and enhanced stability. ${ }^{\mathbf{1}, 2}$ Among the various conducting polymers, polyaniline (PANI) is widely investigated because of its unique redox tunability, sensitivity, excellent process ability together with the presence of a number of intrinsic redox states that substantially enhance the potential application of PANI in biomedical devices. $^{2-6}$ Composites of PANI containing amino groups and gold nanoparticles (AuNPs) possessing high affinity for thiols help in the interaction of the PANI-Au nanocomposite with biomolecules. ${ }^{7,8}$ Moreover, the large surface area to volume ratio of the nanoparticles provides suitable transducer surface for attaching the biomolecules. ${ }^{9}$ Afzal et al. examined that the electrical conductivity as well as thermal stability of composite can be increased with respect to the concentration of AuNPs in the PANI-Au nanocomposite..$^{\mathbf{1 0 1 1}}$ Liu et al. have fabricated polystyrene-polyaniline-Au composite based biosensor and investigated that fabricated sensor shows excellent redox ability in a wide $\mathrm{pH}$ range with high catalytic activity. ${ }^{12}$ Tian et al. have prepared polyaniline-gold nanoparticles multilayer films by

Biomedical Instrumentation Section, CSIR-National Physical Laboratory, New Delhi-110012, India. E-mail: sumanagajjala@gmail.com; Tel: +91-11-42342439

$\uparrow$ Electronic supplementary information (ESI) available. See DOI: 10.1039/c5ra06146f layer by layer method and showed that sensor can be used with very good electroactivity in a neutral $\mathrm{pH}$ environment. ${ }^{13}$ Feng et al. also have described the Au-PANI matrix to construct sensor and has showed the sensor is having high catalytic activity and enhanced detection sensitivity. ${ }^{\mathbf{1 4}}$

Gonorrhoea has been reported as second most common bacterial sexually transmitted disease (STD). ${ }^{15}$ An etiologic pathogen named $N$. gonorrhoeae causes gonorrhoea and its related clinical syndromes such as urethritis, cervicitis, salpingitis, bacteremia, arthritis etc. ${ }^{\mathbf{1 6}}$ Globally, an estimated 12 million people are infected every year, and the majority of infections are believed to occur in developing countries. ${ }^{17}$ The incidence of gonorrhoea varies with age i.e. seventy-five percent of cases occur in persons aged less than 30 years. Gonorrhoea infection spreads in healthy person by physical contact with the mucosal surfaces of an infected sexual partner. ${ }^{18}$ During birth, ophthalmic gonococci infection may be develop in new born baby due to passage of infected mother's genital tract. The main seriousness of this infection is caused by its asymptomatic behavior i.e. upto $80 \%$ of women and $10 \%$ of men, are asymptomatic and gonorrhoea is co-factor for other STD like HIV. Various techniques are available for the detection of gonorrhoea which includes culture, gram stain test and nucleic acid amplification test (NAAT). Culture has been used most widely, but it can be used for the detection of living cells only and needs multiple steps for processing specimens with addressing of quality assurance at each step. ${ }^{\mathbf{1 9 2 0}}$ Gram stain test which is having specificity (>99\%) and sensitivity (>95\%) for 
symptomatic men or women but, for asymptomatic men or women test is less useful, because of lower sensitivity. ${ }^{21}$ NAATs test is applicable for variety of specimen types including endocervical swabs, vaginal swabs and urethral swabs in men but sensitivity of this test varies with its type and is very expensive. ${ }^{22}$ These conventional techniques are having limitations in terms of time consumption which also need skilled laboratory personnel. ${ }^{18}$ Therefore, there is an immediate demand for the development of low cost, reliable, rapid biosensor for diagnosis of Neisseria gonorrhoeae.

In the present work, efforts have been made to synthesize PANI-Au nanocomposite using chemical route and chronopotentiometric techniques. Further, the bioelectrodes have been fabricated by immobilizing probe sequence specific to Neisseria gonorroheae on to the deposited films.

\section{Materials and methods}

\subsection{Chemical and reagents}

Aniline, aurochloric acid $\left(\mathrm{AuCl}_{3}\right)$, sodium citrate, methylene blue, tris base, ethylene diamine tetra acetic acid (EDTA), potassium monohydrogen phosphate, potassium dihydrogen phosphate, oligonucleotide probes (20 bases), ammonium peroxydisulfate, copper sulphate, dodecyl benzene sulfonic acid (DBSA) and all other reagents and solvents have been procured from Sigma-Aldrich (India). Indium-tin oxide (ITO) coated glass plates with resistivity $30 \Omega$ have been purchased from Balzers, UK. All other chemicals were of analytical grade and used without purification. Deionized water (resistance $18.2 \mathrm{M} \Omega \mathrm{cm}$ ) from the Millipore water purification system was used for the preparation of desired aqueous solutions. DNA probes used for hybridization are as follows.

Probe: thiol-5'-CCGGTGCTTCATCACCTTAG-3';

Complementary target: $5^{\prime}$-CTAAGGTGATGAAGCACCGG-3';

Non-complementary target:

5'-GTATGGTGATCAAGCTCCCG-3';

One-base mismatch DNA:

5'-CTAAGTTGATGAAGCACCGG-3'

Two-base mismatch DNA: 5'-CTAAGTTGATGAAACACCGG-3'; Three-Base mismatch DNA:

$$
5^{\prime} \text {-CTAAGTTGATGAAAAGACCGG-3' } .
$$

\subsection{DNA extraction and processing of microbial samples}

DNA has been isolated from a panel of strains comprising of control strains of $N$. gonorrhoeae, Escherichia coli, Neisseria sicca, Staphylococcus aureus and Klebseilla pneumoniae for specificity studies. For this, $200 \mu \mathrm{l}$ sterile MilliQ water is taken in a $2 \mathrm{ml}$ eppendorf and a suspension of colonies is made and then vortexed. The suspension is boiled for about $15 \mathrm{~min}$ and is centrifuged at $10000 \mathrm{rpm}$ for about $10 \mathrm{~min}$. To this, equal volume $(200 \mu \mathrm{l})$ of $24: 1(\mathrm{v} / \mathrm{v})$ chloroform: iso-amyl alcohol is added followed by centrifuging at $12000 \mathrm{rpm}$ for about $10 \mathrm{~min}$. The aqueous layer containing DNA is carefully pipetted out and is kept at $-20{ }^{\circ} \mathrm{C}$ prior to being used. ${ }^{32}$

\subsection{Preparation of gold nanoparticles}

Gold nanoparticles (AuNPs) were synthesized using previous reported method with slight modification. In brief, $1 \mathrm{ml}$ of sodium citrate $(1 \% \mathrm{w} / \mathrm{v})$ has been added drop wise in $10 \mathrm{ml}$ of $\mathrm{AuCl}_{3}(2 \mathrm{mM})$ with continuous stirring for $30 \mathrm{~min}$ at $80^{\circ} \mathrm{C}$ till the color of solution changes from pale yellow to ruby red, indicating the formation of colloidal AuNPs. ${ }^{23}$

\subsection{Fabrication of electrochemically deposited PANI-Au/ITO electrodes}

Fig. 1(a) illustrates the electrochemical (EC) polymerization of aniline $(0.1 \mathrm{M})$ which has been carried out using $1 \mathrm{M} \mathrm{HCl}$ in the presence of AuNPs (5 mM) onto ITO electrode $\left(0.5 \mathrm{~cm}^{2}\right)$. Polymerization was done chronopotentiometrically using $\mathrm{Ag} / \mathrm{AgCl}$ as the reference electrode, platinum (Pt) as the counter electrode, and ITO as the working electrode at $150 \mu \mathrm{A}$ for $300 \mathrm{~s}$ (EC-PANI-Au/ITO). ${ }^{24}$

\subsection{Fabrication of electrophoretically deposited PANI-Au/ ITO electrodes}

PANI-Au nanocomposite has been synthesized by mixing 100 $\mathrm{ml}$ of diluted AuNPs (5 mM) in aniline (0.1 M) and polymerization has been carried out in presence of DBSA with continuous stirring till the color of solution changes from red to turbid white. ${ }^{25}$ Solution was cooled down to $0{ }^{\circ} \mathrm{C}$ after which $1 \mathrm{ml}$ of $\mathrm{CuSO}_{4}$ and $5 \mathrm{ml}$ ammonium peroxydisulfate $(1 \mathrm{M})$ was added. After six hours, dark green mixture was formed, which was centrifuged, collected and dispersed in $10 \mathrm{ml}$ of ethanol. The electrophoretic deposition (EPD) was carried out at $50 \mathrm{~V}$ for $30 \mathrm{~s}$ using a two electrode system (shown in Fig. 1(b)) in which ITO electrode was used as cathode and thin platinum foil as anode, which results in the formation of PANI-Au nanocomposite films (EPD-PANI-Au/ITO).

\subsection{Characterization}

The structural and morphological characterization of PANI-Au nanocomposite have been carried out using transmission electron microscope (TEM, Hitachi Model, H-800) and scanning electron microscope (SEM, JEOLJSM-6700F, $10 \mathrm{kV}$ ). Dynamic light scattering (DLS) measurements were performed with a Zetasizer Nano-ZS90 (Malvern Instruments) at a scattering angle of $90^{\circ}$ and at constant temperature of $25^{\circ} \mathrm{C}$ to determine the zeta potential and particle size of GNPs and PANI-Au nanocomposite. Fourier transform infrared (FT-IR) spectroscopic measurements have been carried out using Perkin-Elmer spectrometer (model Spectrum BX) at $25{ }^{\circ} \mathrm{C}$. Contact angle (CA) has been recorded using contact angle meter (Data Physics OCA15EC). Electrochemical characterizations have been conducted on an Autolab potentiostat/galvanostat (Eco Chemie, Utrecht, The Netherlands) using a three-electrode cell with PANI-Au/ITO as working electrode, platinum as an auxiliary electrode and $\mathrm{Ag} / \mathrm{AgCl}$ as a reference electrode in phosphate buffer (PBS, $100 \mathrm{mM}, \mathrm{pH}$ 7.0, 0.9\% NaCl) containing $5 \mathrm{mM}$ $\left[\mathrm{Fe}(\mathrm{CN})_{6}\right]^{3-/ 4-}$. Subsequently, the DPV measurements of pDNA/ EPD-PANI-Au/ITO electrodes have been carried out in $50 \mu \mathrm{M}$ 

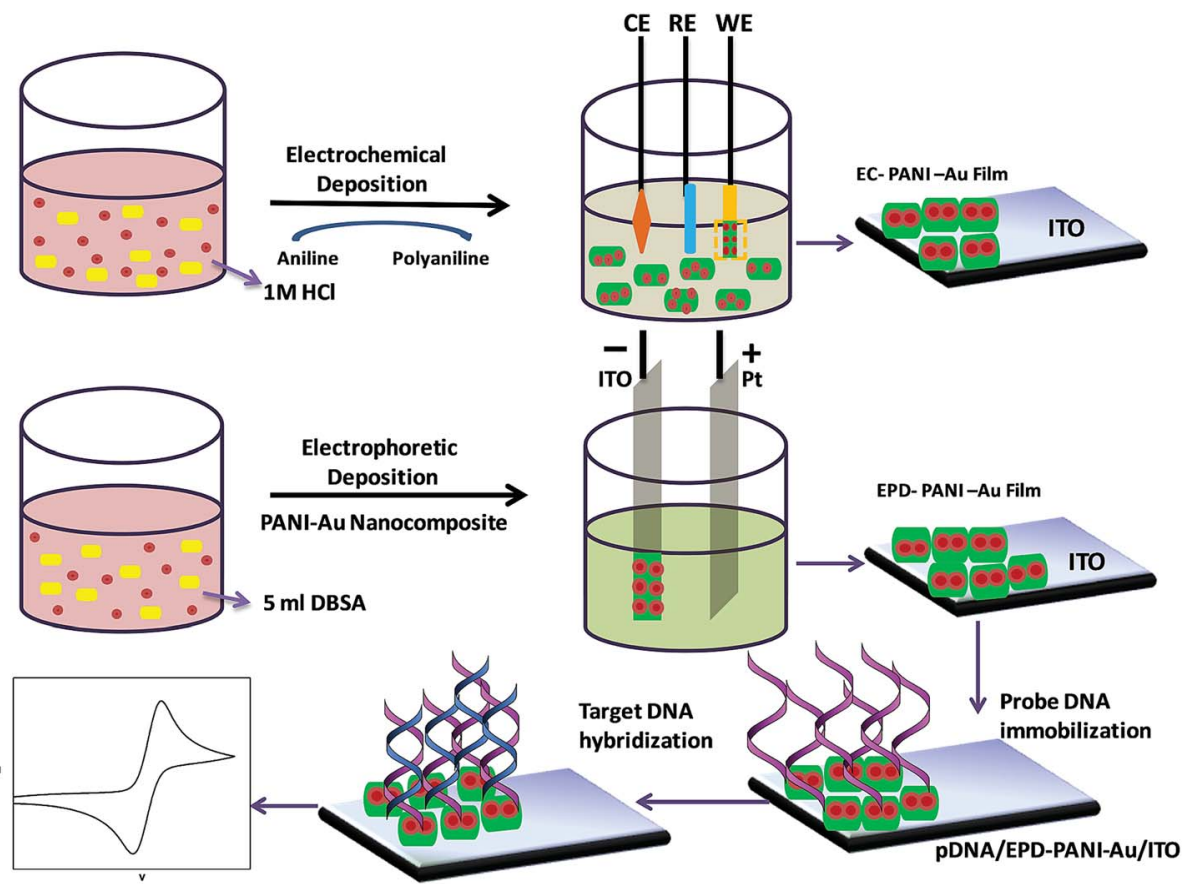

Fig. 1 Schematic illustration for the preparation of (i) electrochemical deposition of PANI-Au nanocomposite on ITO electrode (ii) electrophoretic deposition of PANI-Au nanocomposite synthesized via chemical route on ITO electrode and fabrication of pDNA/EPD-PANI-Au/ITO bioelectrode.

$\mathrm{MB}$, pre-treatment at $+0.5 \mathrm{~V}$ for $10 \mathrm{~s}$, at step potential of $5 \mathrm{mV}$ and modulation amplitude of $250 \mathrm{mV}$.

\subsection{Fabrication of bioelectrodes for $N$. gonorrhoeae detection}

Composites prepared by both the techniques (EC-PANI-Au/ITO, EPD-PANI-Au/ITO) have been utilized for the biosensor fabrication by immobilizing thiolated oligonucleotide (thiol-DNA, 20 $\mu \mathrm{l}, 1.0 \mu \mathrm{M}$ ) specific to $N$. gonorrhoeae having 20 base pairs in a humid chamber at $25{ }^{\circ} \mathrm{C}$ and incubated for about $8 \mathrm{~h}$. These modified electrodes were washed with tris buffer several times to remove any unbound pDNA. The hybridization studies of pDNA/EPD-PANI-Au bioelectrode with target DNA sequences (complementary DNA concentration range $\left(1 \times 10^{-16} \mathrm{M}\right.$ to $1 \times$ $\left.10^{-6} \mathrm{M}\right)$, non-complementary, one-base mismatch, two base mismatch and three base mismatch) have been carried out in a humid chamber for $60 \mathrm{~s}$ at $25^{\circ} \mathrm{C}$.

\section{Results and discussions}

\subsection{Surface characterization}

TEM studies were conducted to confirm the particle size and the core structure of the PANI-Au nanocomposite. Fig. 2(a) represents TEM image of AuNPs having spherical structure with a diameter in the range of 30-40 $\mathrm{nm}$. The TEM images of ECPANI-Au (Fig. 2(b)) and EPD-PANI-Au (Fig. 2(c)) indicate AuNPs as dark spots encapsulated by gray PANI shells. However, it has been observed that AuNPs are well dispersed in PANI synthesized by chemical route (Fig. 2(d)) in comparison to that synthesized by direct electrochemical polymerization of PANI, where accumulation of AuNPs has been observed.

The particle size distribution and zeta potential of the AuNPs and PANI-Au have been determined via dynamic light scattering and is shown in Fig. S1. $\dagger$ The average size of formed AuNPs is about $38 \mathrm{~nm}$ with a polydispersity index of $\sim 0.5$ (Fig. S1(a)†), while the surface charge determined using the

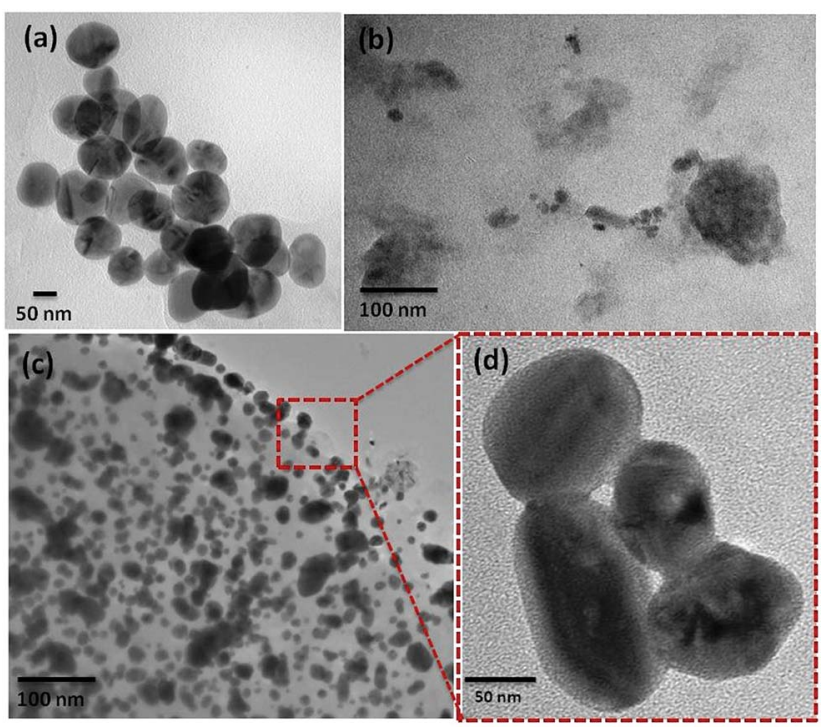

Fig. 2 TEM images of (a) AuNPs (b) electrochemical synthesized PANI-Au nanocomposite. PANI-Au nanocomposite synthesized by chemical route (c) at lower magnification (d) at higher magnification. 
Smoluchowski method, is found to be $-25.6 \mathrm{mV}$ (Fig. S1(b) $\dagger$ ). ${ }^{26}$ However, the zeta potential value of PANI-Au nanocomposite has been found to be $43.2 \mathrm{mV}$ (Fig. S1(c)†) which indicates that the formed nanocomposites are quite stable, which is the requisite property for the electrophoretic deposition.

Brunauer-Emmett-Teller (BET) measurement was performed for evaluating the specific surface area of the EC-PANI$\mathrm{Au}$ nanocomposite and PANI-Au nanocomposite synthesized by chemical route. For BET analysis both the nanocomposites were degassed in a vacuum at $150{ }^{\circ} \mathrm{C}$ for $5 \mathrm{~h}$. The surface area was calculated on the basis of BET theory and shown in Fig. S2. $\dagger^{27}$ The BET surface area for PANI-Au nanocomposite synthesized by chemical route was found to be $43.17 \mathrm{~m}^{2} \mathrm{~g}^{-1}$ (Fig. S2; curve $(\mathrm{ii}) \dagger$ ), which is higher than the value for EC-PANI-Au nanocomposite $\left(32.23 \mathrm{~m}^{2} \mathrm{~g}^{-1}\right.$; Fig. $\mathrm{S} 2$, curve (i) $\left.\dagger\right){ }^{28}$ The value indicates that the nanocomposite synthesized by chemical route is having large surface area in comparison to nanocomposite synthesized by electrochemical route.

SEM images of EC-PANI-Au/ITO electrode (Fig. 3(a)) and EPD-PANI-Au/ITO electrode (Fig. 3(c)) show a uniformly distributed three-dimensional structure which suggests homogeneity in the matrix. However, it has been observed that more intensified porous structures were formed in case of EPD-PANI$\mathrm{Au} / \mathrm{ITO}$ where AuNPs are well distributed. After immobilization of pDNA on EC-PANI-Au/ITO electrode (Fig. 3(b)) and EPDPANI-Au/ITO electrode (Fig. 3(d)) globular structure has been noticed. Interestingly, it has been perceived that the immobilization of pDNA on the EC-PANI-Au/ITO electrode is not uniform (inset Fig. 3(b)). However, the even distribution of the pDNA can be easily observed for the EPD-PANI-Au/ITO electrode (inset Fig. 3(d)) which is due to enhanced porosity and increased surface roughness of EPD-PANI-Au/ITO electrode. Furthermore, a magnified view of the pDNA/EPD-PANI-Au/ITO electrode surface (inset Fig. 3(d)) reveals the presence of globules in isolation that exclude the probability of steric hindrance to target oligonucleotide and hence plays an important role in determining the performance of the sensor. ${ }^{29}$

Contact angle (CA) measurements have been carried out using the sessile drop method to investigate immobilization of

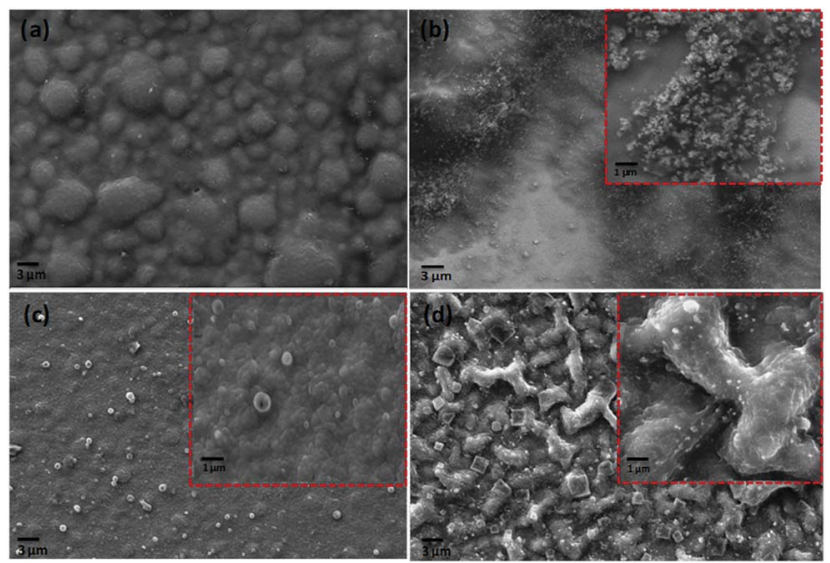

Fig. 3 SEM images of (a) EC-PANI-Au/ITO (b) pDNA/EC-PANI-Au/ ITO (c) EPD-PANI-Au/ITO and (d) pDNA/EPD-PANI-Au/ITO.
pDNA on the surface of PANI-Au matrix. Change in contact angle of immobilized probe in respect of matrix shows the hydrophilicity/hydrophobicity of the prepared bioelectrode which in turn can be related to immobilization of pDNA. CA of ITO electrode (Fig. 4(a)) was found to be $78.3^{\circ}$, which decreases to $65.4^{\circ}$ for EC-PANI-Au/ITO electrode (Fig. 4(b)) and to $42.2^{\circ}$ for EPD-PANI-Au/ITO electrode (Fig. 4(c)). The decrease in CA of electrode can be related to the presence of hydrophilic functional groups (-NH and $-\mathrm{COOH})$. The decrease in CA to $16.4^{\circ}$ (Fig. 4(d)) for EC-PANI-Au/ITO electrode and to $10.2^{\circ}$ for EPD-PANI-Au/ITO electrode (Fig. 4(e)) after the immobilization of pDNA, may be due to the enhancement of hydrophilicity caused by the presence of negatively charged phosphodiester backbone of pDNA. ${ }^{26}$ With variation in time, the value of CA decreases and becomes constant after $8 \mathrm{~h}$, indicating the complete immobilization of DNA in this duration.

To determine the interactions between AuNPs, PANI and pDNA, FT-IR spectrum of EPD-PANI-Au/ITO and pDNA/EPDPANI-Au/ITO electrodes have been performed. Peaks at 1576 and $1495 \mathrm{~cm}^{-1}$ (Fig. S3(a)) $\dagger$ for PANI/ITO films have been attributed to $\mathrm{C}=\mathrm{C}$ stretching deformation of quinoid and benzenoid rings respectively, showing oxidation state of PANI as reported in literature. ${ }^{30}$ Whereas, for EPD-PANI-Au/ITO electrode, there is a shift in the peaks to 1590 and $1511 \mathrm{~cm}^{-1}$ (Fig. S3(b) †). Peaks at 1300 and $1140 \mathrm{~cm}^{-1}$ in Fig. S3(a) $\dagger$ corresponds to $\mathrm{C}-\mathrm{N}$ stretching of secondary aromatic amine and aromatic $\mathrm{C}-\mathrm{H}$ in-plane bending respectively, whereas in Fig. S3(b) $\dagger$ there is shift in the peaks at 1315 and $1149 \mathrm{~cm}^{-1}$. The shifting in the peaks shows that the $\mathrm{C}-\mathrm{N}$ bonds within the composite are influenced by the AuNPs (Fig. S3(b) $\dagger$ ). Further, the shift in energy to higher energy levels indicates that the $\mathrm{Au}$ directly influences the electron density of the $\mathrm{C}-\mathrm{N}$ bond. ${ }^{\mathbf{3 1}}$ The

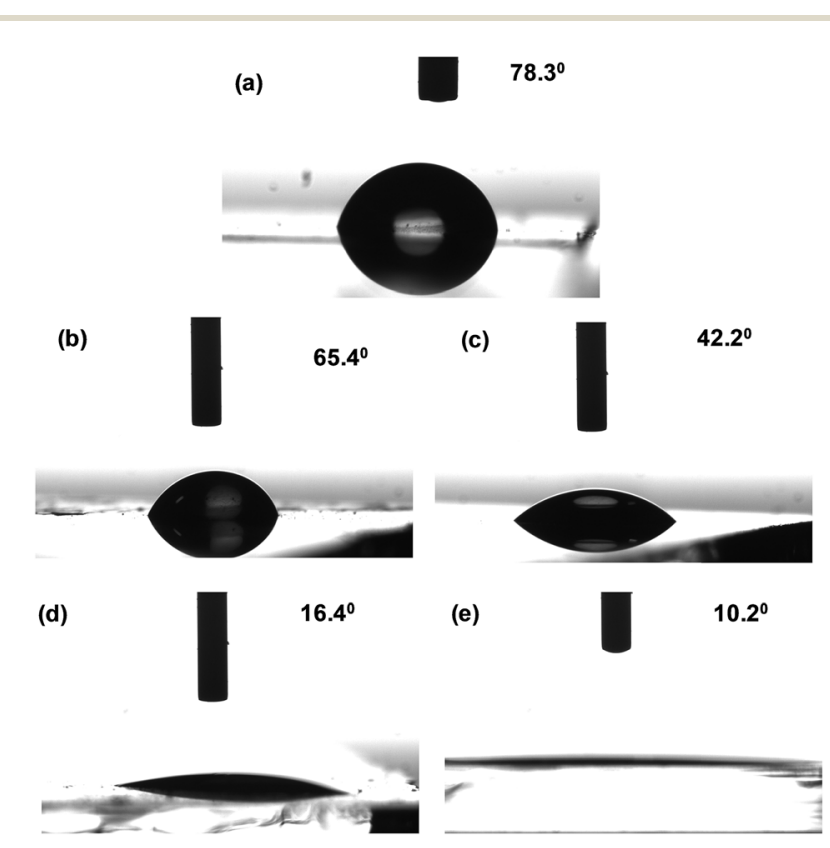

Fig. 4 Contact angle measurements of (a) bare ITO (b) EC-PANI-Au/ ITO (c) EPD-PANI-Au/ITO (d) pDNA/EC-PANI-Au/ITO and (e) pDNA/ EPD-PANI-Au/ITO. 
peak seen at $794 \mathrm{~cm}^{-1}$ in Fig. S3(a)† related to out-of-plane deformation vibration of $\mathrm{C}-\mathrm{H}$. The shifting in the peaks to high energy in Fig. S3(b) $\dagger$ at $833 \mathrm{~cm}^{-1}$ for PANI-Au in comparison to the PANI films directly related to differences in chemistry and electron density. ${ }^{31}$ FT-IR spectrum of pDNA/EPDPANI-Au/ITO electrode (Fig. S3(c) †) shows absorption bands at $1036 \mathrm{~cm}^{-1}$ and $1398 \mathrm{~cm}^{-1}$ which are associated with antisymmetric stretching vibration of $\mathrm{P}-\mathrm{O}-\mathrm{C}$ and symmetric stretching vibration of $\mathrm{P}=\mathrm{O}$ of the phosphoric acid group, respectively. Whereas, the bands at $1512 \mathrm{~cm}^{-1}$ and 1603 $\mathrm{cm}^{-1}$ are attributed to carbonyl stretching vibration and $\mathrm{C}=\mathrm{C}$ bonds in the purine and pyrimidine.

\subsection{Electrochemical characterization}

Electrochemical characterization has been conducted using cyclic voltammetry (CV) in phosphate buffer saline (100 mM, pH $7.0,0.9 \% \mathrm{NaCl})$ containing $5 \mathrm{mM}\left[\mathrm{Fe}(\mathrm{CN})_{6}\right]^{3-/ 4-}$ to examine the electro-active behavior of the electrodes (Fig. S4†). There was a decrease in the peak current for both EC-PANI-Au/ITO $(0.46 \mathrm{~mA})$ and EPD-PANI-Au/ITO $(0.60 \mathrm{~mA})$, as compared to ITO $(1.7 \mathrm{~mA})$ electrode at a scan rate of $50 \mathrm{mV} \mathrm{s}^{-1}$ (Fig. S4(a) $\dagger$ ). Interestingly for EPD-PANI-Au/ITO electrode the peak current was higher than EC-PANI-Au/ITO which may be due to strong physio-chemical interaction between AuNPs and PANI which is due to charge transfer process from the positively charged imine nitrogen of PANI to the negatively charged AuNPs. This results in uniform distribution of AuNPs in the conducting polymeric chains of PANI without any aggregation resulting in a favorable pathway for the transfer of electrons. ${ }^{32}$ Moreover, the large surface area of the PANI-Au nanocomposite is due to presence of AuNPs provides more active sites for the electron transfer and effective charge migration through the polymer. In case of EC-PANI-Au there is possibility that insufficient time is available for the binding of AuNPs on the surface of PANI which may result in phase separation. ${ }^{25,33,34}$ After the immobilization of probe DNA there was a large increase in the peak current for EPD-PANI-Au/ITO electrode (1.14 $\mathrm{mA})$ in comparison to ECPANI-Au/ITO electrode $(0.83 \mathrm{~mA})$, which suggest that there is immobilization of more probe DNA onto EC-PANI-Au/ITO electrode that creates a negative charge on the surface thus repels the negatively charged redox marker, $\left.\mathrm{Fe}(\mathrm{CN})_{6}\right]^{3-/ 4-}$.

The CV investigations at various potential scan rates $(v ; 10$ to $300 \mathrm{mV} \mathrm{s}^{-1}$ ) have been performed onto EPD-PANI-Au/ITO electrode (Fig. S4(b) $\dagger$ ) and EC-PANI-Au/ITO electrode (Fig. S4(c) $\dagger$ ). As the scan rate increases, the anodic peak potential shifts to more positive value and the cathodic peak to more negative value, suggesting a quasi-reversible process. The positive and negative peaks correspond to the oxidation and reduction of the $\left[\mathrm{Fe}(\mathrm{CN})_{6}\right]^{3-/ 4-}$ respectively. The peak current values of these electrodes have linear relationship with respect to the square root of scan rate indicating the existence of diffusion-controlled electrochemical reaction (Fig. S4† inset). Both anodic and cathodic peak potentials are found to change linearly with respect to $\log$ of $v$, which agrees with Laviron's theory: $:^{35}$

$$
\begin{gathered}
E_{\mathrm{pa}}=E^{\circ}+X \ln \left[(1-\alpha) F v / R T k_{\mathrm{s}}\right] \\
E_{\mathrm{pc}}=E^{\circ}+Y \ln \left[\alpha F v / R T k_{\mathrm{s}}\right]
\end{gathered}
$$

$\ln k_{\mathrm{s}}=\alpha \ln (1-\alpha)+(1-\alpha) \ln \alpha-\ln (R T / n F v)$

$$
-\alpha(1-\alpha) n F \Delta E_{\mathrm{p}} / R T \text {. }
$$

where $\alpha$ denotes electron transfer coefficient and $k_{\mathrm{s}}$ denotes the charge transfer rate constant and $X=R T /(1-\alpha) n f$ and $Y=R T /$ $\alpha n f$ are the slopes of straight line plotted by $\ln v$ versus the anodic peak potential $\left(E_{\mathrm{pa}}\right)$ and cathodic peak potential $\left(E_{\mathrm{pc}}\right)$ respectively. The values of $\alpha$ and $k_{\mathrm{s}}$ for EPD-PANI-Au/ITO electrode is found to be 0.92 and $0.0848 \mathrm{~s}^{-1}$ respectively. Similarly, for EC-PANI-Au/ITO electrode the values for $\alpha$ is found to be 0.85 and $k_{\mathrm{s}}$ is $0.0368 \mathrm{~s}^{-1}$. By using Randles-Sevcik equation: ${ }^{30}$

$$
I_{\mathrm{p}}=\left(2.99 \times 10^{5}\right) \alpha^{1 / 2} n^{3 / 2} A C D^{1 / 2} v^{1 / 2}
$$

the diffusion coefficient $(D)$ has been calculated as $6.9 \times 10^{-15}$ $\mathrm{cm}^{2} \mathrm{~s}^{-1}$ for EPD-PANI-Au/ITO electrode and $2.6 \times 10^{-15} \mathrm{~cm}^{2}$ $\mathrm{s}^{-1}$ for EC-PANI-Au/ITO electrode. Here $C$ is the molar concentration of $\left[\mathrm{Fe}(\mathrm{CN})_{6}\right]^{3-/ 4-}, n$ is the number of transferred electrons for the redox reaction and $v$ is the scan rate $(50 \mathrm{mV}$ $\mathrm{s}^{-1}$ ). The effective surface areas $(A)$ of the EPD-PANI-Au/ITO electrode and EC-PANI-Au/ITO electrode have been calculated using the eqn (5). and found to be $0.53 \mathrm{~mm}^{2}$ and $0.48 \mathrm{~mm}^{2}$ respectively.

$$
A=S /\left(2.99 \times 10^{5}\right) \alpha^{1 / 2} n^{3 / 2} C D^{1 / 2}
$$

These enhanced kinetic parameters for EPD-PANI-Au/ITO electrode in comparison to the EC-PANI-Au/ITO electrode are due to better charge transfer and electrostatic interaction between PANI and AuNPs (Table 1).

\subsection{Genosensor response studies}

Differential pulse voltammetry (DPV) has been used to study the electrochemical response of the fabricated pDNA/EPD-PANI-Au/ ITO by immobilizing target DNA using methylene blue (MB, 20 $\mu \mathrm{M})$ as redox hybridization indicator. $\mathrm{MB}$ is known to have affinity with the nitrogenous guanine bases of pDNA and undergo reduction by oxidizing them. ${ }^{36-38}$ In Fig. 5(a) bar diagram showing the $\mathrm{MB}$ peak current is highest $\left(1.07 \times 10^{-5} \mathrm{~A}\right)$ for pDNA/EPD-PANI-Au/ITO which is due to the presence of nitrogenous bases, but after incubation with complementary target sequence, peak current decreases to $5.8 \times 10^{-6} \mathrm{~A}$. This may be due to the nonaccessibility of nitrogenous bases on the electrode surface due to the formation of duplex. After incubation of the bioelectrode with non-complementary DNA, no significant change in $\mathrm{MB}$ peak current $\left(1.09 \times 10^{-5} \mathrm{~A}\right)$ was observed in comparison to the pDNA/EPD-PANI-Au/ITO which indicates non-hybridization at the electrode surface. However, after incubating the bioelectrode with one base, two base and three base mismatch DNA sequences the peak current substantial decreases in comparison with the noncomplementary DNA sequence showing that the biosensor can even distinguish a single nucleotide variation in target DNA sequence. The response 
Table 1 Kinetic parameters calculated for the EPD-PANI-Au/ITO electrode and EC-PANI-Au/ITO electrode

\begin{tabular}{|c|c|c|c|c|}
\hline Name of electrode & $\begin{array}{l}\text { Electron transfer } \\
\text { coefficient, } \alpha\end{array}$ & $\begin{array}{l}\text { Charge transfer } \\
\text { rate constant, }\left(k_{\mathrm{s}} / \mathrm{s}^{-1}\right)\end{array}$ & $\begin{array}{l}\text { Effective surface } \\
\text { area, }\left(A_{\mathrm{eff}} / \mathrm{mm}^{2}\right)\end{array}$ & $\begin{array}{l}\text { Diffusion coefficient, } \\
D\left(\mathrm{~cm}^{2} \mathrm{~s}^{-1}\right)\end{array}$ \\
\hline EPD-PANI-Au/ITO & 0.92 & 0.0848 & 0.53 & $6.9 \times 10^{-15}$ \\
\hline EC-PANI-Au/ITO & 0.85 & 0.0368 & 0.48 & $2.6 \times 10^{-15}$ \\
\hline
\end{tabular}

characteristics of the electrode as a function of complementary DNA concentration ranging from $1 \times 10^{-16}$ to $1 \times 10^{-6} \mathrm{M}$ shown in Fig. 5(b). ${ }^{39}$ The results reveals that with decrease in concentration of complementary target DNA, there is an increase in the $\mathrm{MB}$ reduction current which can be correlated to extent of hybridization. ${ }^{40}$ Fig. 5 (c) shows the peak current values of the sensor which attributes a linear correlation to the $\log \left[\right.$ target concentration] from $1 \times 10^{-6} \mathrm{M}$ to $1 \times 10^{-16} \mathrm{M}$ and follows eqn (6).
MB oxidation current $I_{\mu \mathrm{A}}=-0.47 \times \log (\operatorname{target} \mathrm{DNA}$ concentration) $-2.8 ; R=0.9963$

The detection limit calculated using the standard equation ( $3 \sigma /$ sensitivity) and was found to be $1 \times 10^{-16} \mathrm{M}$, where $\sigma$ is standard deviation of the electrode without hybridization..$^{\mathbf{4 1}}$ The comparison of response characteristics of EPD-PANI-Au nanocomposite with other PANI based nanocomposites reported in literature for nucleic acid detection shows that this sensor (a)

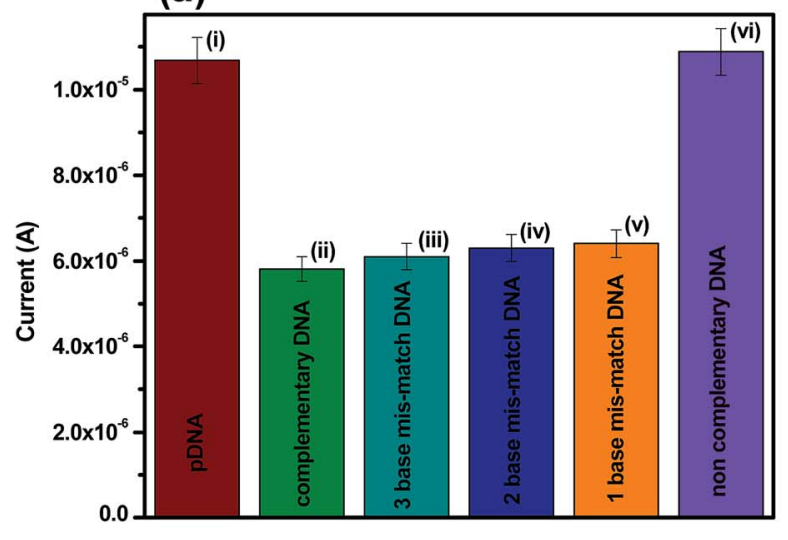

(c)

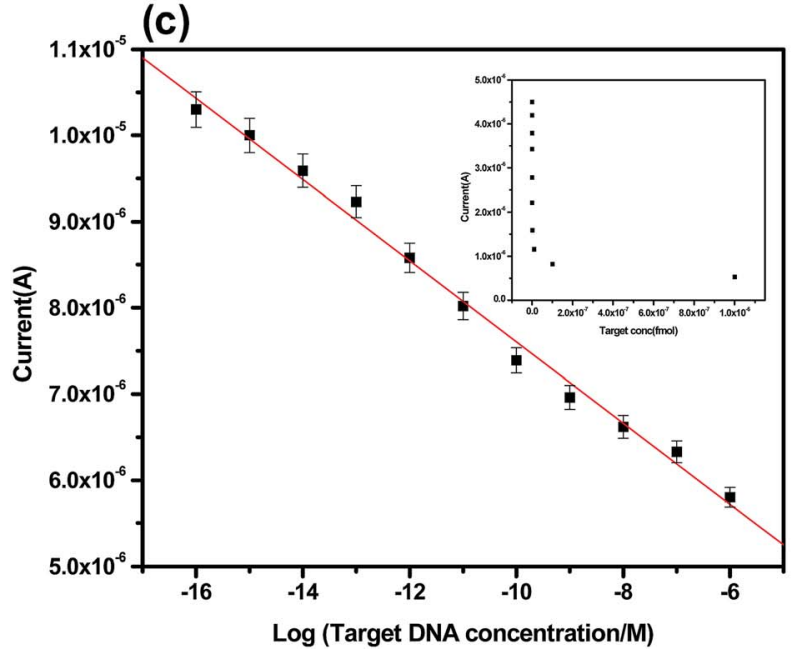

(b)

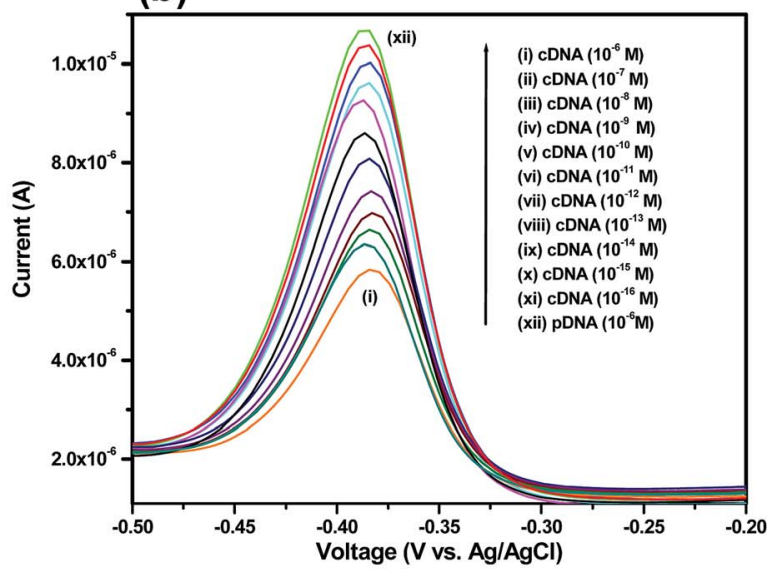

(d)

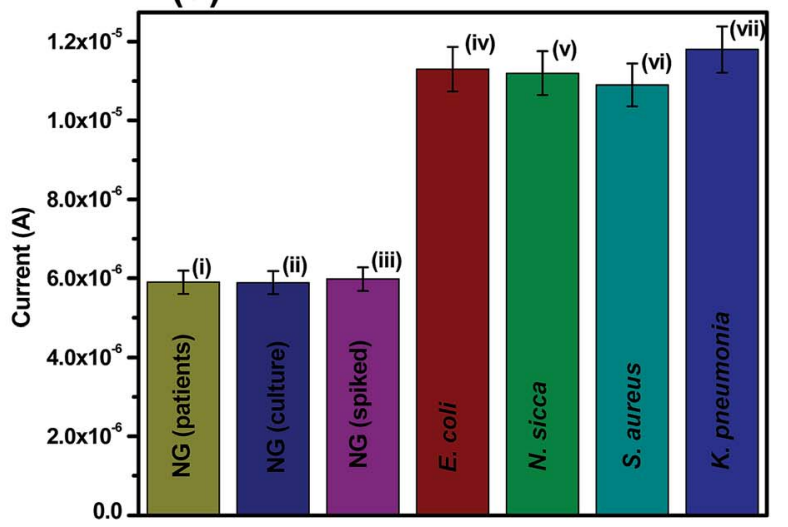

Fig. 5 Bar diagram showing the (a) DPV response of (i) pDNA/EPD-PANI-Au/ITO after the incubation with (ii) complementary DNA (iii) three base mis-match (iv) two base mis-match (v) one base mis-match (vi) noncomplementary DNA. (b) Sensing performance of pDNA/EPD-PANI$\mathrm{Au} / \mathrm{ITO}$ electrode as the function of complementary DNA concentration $\left(1 \times 10^{-6}\right.$ to $\left.1 \times 10^{-16} \mathrm{M}\right)$ (c) linearity plot showing the relationship between the MB peak current values with log[target DNA concentration]. Inset figure shows MB peak current values as a function of target DNA concentration. (d) Bar diagram showing the incubation of pDNA/EPD-PANI-Au/ITO with real samples of (i) $N$. gonorrhoeae patient (ii) N. gonorrhoeae cultured (iii) spiked N. gonorrhoeae (iv) E. coli (v) N. sicca (vi) S. aureus (vii) K. pneumonia. 
Table 2 Comparison of the response characteristics of EPD-PANI-Au nanocomposite with other Polyaniline based nanocomposites

\begin{tabular}{|c|c|c|c|c|c|c|c|}
\hline S. no. & Electrode & $\begin{array}{l}\text { Method of } \\
\text { immobilization }\end{array}$ & $\begin{array}{l}\text { Electrochemical } \\
\text { technique }\end{array}$ & $\begin{array}{l}\text { Detection } \\
\text { limit }(\mathrm{M})\end{array}$ & $\begin{array}{l}\text { Detection } \\
\text { range }(\mathrm{M})\end{array}$ & $\begin{array}{l}\text { Hybridization } \\
\text { time }\end{array}$ & Ref. \\
\hline 1 & BdNG-avidin-nsPANI/ITO & Biotin-avidin coupling & DPV, CV & $0.5 \times 10^{-15}$ & $\begin{array}{l}1 \times 10^{-16} \text { to } \\
1 \times 10^{-6}\end{array}$ & $60 \mathrm{~s}$ & 37 \\
\hline 2 & $\begin{array}{l}\text { GCE coating polyaniline } \\
\text { nanowire }\end{array}$ & EDC/NHS & DPV, CV & $1 \times 10^{-12}$ & $\begin{array}{l}2.25 \times 10^{-12} \text { to } \\
2.25 \times 10^{-10}\end{array}$ & $30 \mathrm{~min}$ & 42 \\
\hline 3 & PANIMWNT/CHIT/CPE & Covalent bonding & EIS, CV & $2.7 \times 10^{-14}$ & $\begin{array}{l}1.0 \times 10^{-13} \text { to } \\
1.0 \times 10^{-7}\end{array}$ & $40 \mathrm{~min}$ & 43 \\
\hline 5 & PANIw/graphene/GCE & EDC/NHS & DPV, CV & $3.25 \times 10^{-13}$ & $\begin{array}{l}2.12 \times 10^{-12} \text { to } \\
2.12 \times 10^{-6}\end{array}$ & $30 \mathrm{~min}$ & 45 \\
\hline 6 & EPD-PANI-Au/ITO & Covalent bonding & DPV, CV & $1 \times 10^{-16}$ & $\begin{array}{l}1 \times 10^{-16} \text { to } \\
1 \times 10^{-6}\end{array}$ & $60 \mathrm{~s}$ & $\begin{array}{l}\text { Present } \\
\text { work }\end{array}$ \\
\hline
\end{tabular}

exhibits higher linear range, sensitivity and stability (as shown in Table 2). ${ }^{37,42-45}$

\subsection{Genosensor response studies with culture, positive patient and spiked samples}

DPV response of the fabricated pDNA/EPD-PANI-Au/ITO bioelectrode with clinical samples has been studied by identifying change in MB oxidation peak current and is shown in bar diagram (Fig. 5(d)). Specificity of the biosensor has been studied by incubating the bioelectrode with DNA extracted from different real samples containing $N$. gonorrhoeae (culture, positive patient, pus sample spiked) and cultures of Escherichia coli, Neisseria sicca, Staphylococcus aureus, Klebseilla pneumonia. The bar diagram shows decrease in the value of peak current after treating with $N$. gonorrhoeae (patient, spiked and culture) samples indicating specific hybridization, however no significant change in the peak current was observed when PDNA/EPDPANI-Au/ITO bioelectrode was treated with DNA samples of non gonorrhoeae species and other gram-negative bacterial samples (E. coli). These results indicate that the fabricated pDNA/EPD-PANI-Au/ITO bioelectrode is highly specific for $N$. gonorrhoeae detection.

\subsection{Stability and reproducibility}

The regeneration of the pDNA/EPD-PANI-Au/ITO bioelectrode has been carried out by dipping it in the buffer solution $(\mathrm{pH}$ 8.0) containing Tris- $\mathrm{HCl}(10 \mathrm{mM})$ and EDTA $(1 \mathrm{mM})$ at $100{ }^{\circ} \mathrm{C}$ for 5 min, followed by cooling in ice bath for about $30 \mathrm{~min}$, which completely removes complementary DNA via thermal denaturation. ${ }^{46,47}$ The MB peak current decreases after each consecutive use of pDNA bioelectrode, as initially it was $1.07 \times 10^{-5} \mathrm{~A}$ and after twelfth use it reached to $0.90 \times 10^{-5} \mathrm{~A}$ (Fig. S5(a) †). It has been found that biosensor can be re-used for 12 times after which the bioelectrodes has lost around $15.3 \%$ of its sensitivity (Fig. S5(a)†). The decrease in MB current after each use can be related to loss of pDNA from the surface of bioelectrode. To investigate the storage stability of the fabricated sensor, three measurements have been recorded each week for over 14 weeks of continuous analysis. The decrease in signal response of the bioelectrode is less than $20 \%$ when stored at $4{ }^{\circ} \mathrm{C}$ (Fig. S5(b)†).

\section{Conclusions}

We have successfully prepared the PANI-Au nanocomposite based electrodes using chronopotentiometric and electrophoretic techniques. The electrochemical and morphological studies clearly reveal that the electrodes prepared by EPD technique have enhanced conductivity and conducive morphology. EPD-PANI-Au/ITO electrodes were further used for the fabrication of genosensor specific for N. gonorrhoeae which provides an increased surface area due to its porous structure. The wide detection range $\left(10^{-6}\right.$ to $\left.10^{-16} \mathrm{M}\right)$, reduced response time ( $60 \mathrm{~s}$ ) with high stability ( 4 weeks) and reusability (12 times) of the genosensor have been successfully demonstrated. The fabricated genosensor has been found to be highly specific to distinguish clinical and real samples of $N$. gonorrhoeae from other non gonorrhoeae and gram negative bacteria species. Attempts should be made to use this PANI-Au nanocomposite platform for detection of other biomolecules and may have significance in point-of-care diagnostics.

\section{Acknowledgements}

We thank Director, National Physical Laboratory, India for providing facilities. A.S and G.S are thankful to CSIR for financial support received under the project ESC-0103. C.M.P. is thankful to CSIR, India, for the award of Senior Research Fellow. S.S. is grateful to UGC, India for the award of Senior Research Fellowship. We thank Prof. B.D Malhotra, Dr A.M Biradar and Ms Monali Singh for their valuable suggestions. We extend our sincere thanks to Dr Seema Sood (AIIMS, New Delhi) for providing the bacterial culture samples.

\section{References}

1 J. Janata and M. Josowicz, Nat. Mater., 2003, 2, 19-24.

2 S. Virji, J. Huang, R. B. Kaner and B. H. Weiller, Nano Lett., 2004, 4, 491-496. 
3 Y. Zhou, H. Itoh, T. Uemura, K. Naka and Y. Chujo, Langmuir, 2002, 18, 277-283.

4 Y. Ma, N. Li, C. Yang and X. Yang, Colloids Surf., A, 2005, 269, 1-6.

5 T. K. Sarma and A. Chattopadhyay, J. Phys. Chem. A, 2004, 108, 7837-7842.

6 J. Han, L. Li and R. Guo, Macromolecules, 2010, 43, 1063610644.

7 W. Yang, J. Liu, R. Zheng, Z. Liu, Y. Dai, G. Chen, S. Ringer and F. Braet, Nanoscale Res. Lett., 2008, 3, 468-472.

8 S. K. Pillalamarri, F. D. Blum, A. T. Tokuhiro and M. F. Bertino, Chem. Mater., 2005, 17, 5941-5944.

9 S. K. Arya, A. Dey and S. Bhansali, Biosens. Bioelectron., 2011, 28, 166-173.

10 A. B. Afzal, M. J. Akhtar, M. Nadeem and M. M. Hassan, J. Phys. Chem. C, 2009, 113, 17560-17565.

11 Z. Peng, L. Guo, Z. Zhang, B. Tesche, T. Wilke, D. Ogermann, S. $\mathrm{Hu}$ and K. Kleinermanns, Langmuir, 2006, 22, 1091510918.

12 Y. Liu, X. Feng, J. Shen, J.-J. Zhu and W. Hou, J. Phys. Chem. $B, 2008,112$, 9237-9242.

13 S. Tian, J. Liu, T. Zhu and W. Knoll, Chem. Mater., 2004, 16, 4103-4108.

14 X. Feng, C. Mao, G. Yang, W. Hou and J.-J. Zhu, Langmuir, 2006, 22, 4384-4389.

15 Z. A. Memish and A. O. Osoba, Int. J. Antimicrob. Agents, 2006, 4, 86-93.

16 D. S. Kellogg, W. L. Peacock, W. E. Deacon, L. Brown and C. I. Pirkle, J. Bacteriol., 1963, 85, 1274-1279.

17 D. Mabey, Medicine, 2010, 38, 216-219.

18 B. S. Shim, Korean J. Urol., 2011, 52, 589-597.

19 R. Singh, G. Sumana, R. Verma, S. Sood, M. K. Pandey, R. K. Gupta and B. D. Malhotra, J. Biotechnol., 2010, 150, 357-365.

20 M. Alam, F. Khayat, A. Al-Kayali and Y. Al-Suhaibani, Indian J. Med. Microbiol., 2002, 20, 37-39.

21 R. L. Cook, S. L. Hutchison, L. Ostergaard, R. S. Braithwaite and R. B. Ness, Ann. Intern. Med., 2005, 142, 914-925.

22 E. H. Koumans, R. E. Johnson, J. S. Knapp and M. E. St. Louis, Clin. Infect. Dis., 1998, 27, 1171-1180.

23 M.-C. Daniel and D. Astruc, Chem. Rev., 2004, 104, 293-346. 24 N. Prabhakar, K. Arora, H. Singh and B. D. Malhotra, J. Phys. Chem. B, 2008, 112, 4808-4816.

25 T. Berzina, A. Pucci, G. Ruggeri, V. Erokhin and M. P. Fontana, Synth. Met., 2011, 161, 1408-1413.
26 C. M. Pandey, A. Sharma, G. Sumana, I. Tiwari and B. D. Malhotra, Nanoscale, 2013, 5, 3800-3807.

27 V. Divya and M. V. Sangaranarayanan, Eur. Polym. J., 2012, 48, 560-568.

28 M. A. Ali, K. Mondal, C. Singh, B. D. Malhotra and A. Sharma, Nanoscale, 2015, 7, 7234-7245.

29 A. A. Ansari, R. Singh, G. Sumana and B. D. Malhotra, Analyst, 2009, 134, 997-1002.

30 C. Dhand, G. Sumana, M. Datta and B. D. Malhotra, Thin Solid Films, 2010, 519, 1145-1150.

31 J. M. Kinyanjui, D. W. Hatchett, J. A. Smith and M. Josowicz, Chem. Mater., 2004, 16, 3390-3398.

32 R. J. Tseng, C. O. Baker, B. Shedd, J. Huang, R. B. Kaner, J. Ouyang and Y. Yang, Appl. Phys. Lett., 2007, 90, 053101.

33 I. Šeděnková, M. Trchová, J. Stejskal and J. Prokes, ACS Appl. Mater. Interfaces, 2009, 1, 1906-1912.

34 Q. Xu, J. Leng, H.-b. Li, G.-j. Lu, Y. Wang and X.-Y. Hu, React. Funct. Polym., 2010, 70, 663-668.

35 J. C. Vidal, E. García and J. R. Castillo, Anal. Chim. Acta, 1999, 385, 213-222.

36 J. Wang, Anal. Chim. Acta, 2002, 469, 63-71.

37 R. Singh, R. Prasad, G. Sumana, K. Arora, S. Sood, R. K. Gupta and B. D. Malhotra, Biosens. Bioelectron., 2009, 24, 2232-2238.

38 O. A. Loaiza, S. Campuzano, M. Lopez-Berlanga, M. a. Pedrero and J. M. Pingarron, Sensors, 2005, 5, 344-363.

39 C. M. Pandey, I. Tiwari and G. Sumana, RSC Adv., 2014, 4, 31047-31055.

40 S. Radhakrishnan, C. Sumathi, A. Umar, S. J. Kim, J. Wilson and V. Dharuman, Biosens. Bioelectron., 2013, 47, 133-140.

41 J.-C. Vidal, E. García-Ruiz and J.-R. Castillo, Electroanalysis, 2001, 13, 229-235.

42 N. Zhu, Z. Chang, P. He and Y. Fang, Electrochim. Acta, 2006, 51, 3758-3762.

43 T. Yang, N. Zhou, Y. Zhang, W. Zhang, K. Jiao and G. Li, Biosens. Bioelectron., 2009, 24, 2165-2170.

44 J. Wilson, S. Radhakrishnan, C. Sumathi and V. Dharuman, Sens. Actuators, B, 2012, 171-172, 216-222.

45 Y. Bo, H. Yang, Y. Hu, T. Yao and S. Huang, Electrochim. Acta, 2010, 56, 2676-2681.

46 C. M. Pandey, R. Singh, G. Sumana, M. K. Pandey and B. D. Malhotra, Sens. Actuators, B, 2010, 151, 333-340.

47 A. Sharma, C. M. Pandey, Z. Matharu, U. Soni, S. Sapra, G. Sumana, M. K. Pandey, T. Chatterjee and B. D. Malhotra, Anal. Chem., 2012, 84, 3082-3089. 